\title{
Evidence for hyperparasitism of coffee rust (Hemileia vastatrix) by the entomogenous fungus, Lecanicillium lecanif, through a complex ecological web
}

\author{
J. Vandermeer ${ }^{\mathrm{ab} \star}$, I. Perfecto ${ }^{\mathrm{b}}$ and H. Liere ${ }^{\mathrm{a}}$

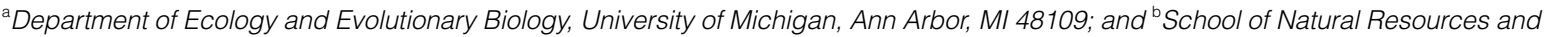 \\ Environment, University of Michigan, Ann Arbor, MI 48109, USA
}

\begin{abstract}
The entomogenous fungus, Lecanicillium lecanii is hyperparasitic on Hemileia vastatrix, the cause of coffee leaf rust in the laboratory, and has frequently been observed attacking it in the field. The existence of a complex ecological web involving the spatially clustered mutualism of an ant (Azteca instabilis) with a scale insect (Coccus viridis), where the scale insect was infected by L. lecanii, prompted a search for a spatial correlation between the attack of L. lecanii on the scale insect and the incidence of rust in a commercial coffee crop. A weak but statistically significant effect of hyperparasitic control of coffee rust was observed on two distinct scales: in a 45-ha plot and on a scale of approximately $10 \mathrm{~m}$. It was concluded that this effect was linked to an indirect effect of the ant-coccid mutualism, where L. lecanii was a parasite of the coccid.
\end{abstract}

Keywords: Azteca instabilis, biological control, Coccus viridis, Coffea arabica, mutualism, spatial analysis

\section{Introduction}

Historically, coffee leaf rust, caused by Hemileia vastatrix, has been a devastating disease the world over, the main cause of abandonment of coffee as a commercial crop in Sri Lanka (then Ceylon), Sumatra and Java, as well as causing panic among producers throughout Central America in the 1980s. As it arrived in the Americas through Brazil, producers aware of its devastating consequences replanted what were held to be resistant cultivars, and reduced or eliminated shade cover, in the hope of curtailing its feared effects. Here it is hypothesized that the disease has antagonists that have acted to reduce its effectiveness in recent years and that those antagonists may be difficult to see directly because they operate through complex ecological relationships, as postulated previously (Avelino et al., 2004). Evidence is presented that the entomogenous fungus Lecanicillium lecanii may be such an antagonist of $H$. vastatrix, operating through a spatially structured ecological network that includes a key ant-insect mutualism which allows for a peculiar spatial structure of this hypothesized antagonist.

*E-mail: jvander@umich.edu

Published online 7 May 2009
While the coffee rust disease remains a major threat to producers all over the world, it has largely become more of an irritant than a disaster, with farms throughout Latin America showing low levels of infection almost every year. Phytosanitary methods, such as heavy pruning of shade trees, use of fungicides and planting of resistant cultivars, seem to have worked to some degree (Fulton, 1984), but even farms where dense shade cover has been retained and rust-resistant cultivars have not been planted have not suffered as severely as feared (McCook, 2006). It is possible that this reduced effect of the disease is partly caused by antagonists or natural enemies and, coupled with the lowered regional infection rate induced by large-scale planting of resistant varieties, has held this disease in relative check (Avelino et al., 2004).

The importance of natural enemies in the phylloplane has been emphasized by several authors (Blakeman $\&$ Fokkema, 1982; Kushalappa \& Eskes, 1989; Andrews, 1992). One of those enemies may be the hyperparasite, L. lecanii [previously known as Cephalosporium lecanii, part of what was previously identified as the Verticillium lecanii species complex (Kouvelis et al., 1999: Zare \& Gams, 2001)], known to colonize $H$. vastatrix under laboratory conditions (Eskes et al., 1991) and observed attacking it in the field (Shaw, 1987; personal observations). Variability for infectivity exists among different 
isolates, ranging from 0 to $80 \%$ in tests on the whitefly Bemisia tabaci (Mor et al., 1996). In the present research, because of an unusual spatial arrangement and a complex web of interactions in a large coffee plantation in Mexico, it was possible to test the hypothesis that L. lecanii contributes to the control of $H$. vastatrix under normal conditions of coffee production.

The particular circumstance that allowed this test was the existence of a spatially extended mutualistic system of an ant, Azteca instabilis (Hymenoptera, Formicidae), and the green coffee scale, Coccus viridis (Hemiptera, Coccidae) mutualist (Vandermeer \& Perfecto, 2006). The ant constructs nests in shade trees of coffee plantations and is distributed in a non-random fashion, forming clusters of satellite nests in local groups of trees (Vandermeer et al., 2008). Coccus viridis occurs throughout the plantation, but never forms large concentrations unless tended by ants, and almost always within clusters of nests of A. instabilis. Coccus viridis commonly contracts a disease, white halo fungus disease, caused by L. lecanii. This insect-fungal disease system is scattered around the coffee farm, but is rarely observed outside of the patches of $A$. instabilis colonies, probably because the scale insect normally escapes the disease as a result of its low local population density. Only when under the influence of the ant does the C. viridis population reach a population density high enough to permit L. lecanii to become epizootic. Additionally, on many occasions during the early summer of 2008, what appeared to be L. lecanii lesions were observed on the surface of $H$. vastatrix uredinia (rust pustules), but only in the vicinity of concentrations of C. viridis under attack by L. lecanii.

This paper postulates that this ant-hemipteran mutualism provides centres of concentrated production of spores of L. lecanii and thus contributes to an elevated level of control over $H$. vastatrix. If this is the case, it should be possible to detect a local spatial effect of the incidence of $H$. vastatrix with regard to the spatial distribution of the ant-hemipteran mutualism.

\section{Methods}

\section{System}

The study was conducted at Finca Irlanda, a 300-ha certified organic coffee farm in the Soconusco region of Chiapas, Mexico $\left(15^{\circ} 11^{\prime} \mathrm{N}, 92^{\circ} 20^{\prime} \mathrm{W}\right)$, established over 100 years ago. The farm is typical of the general ecosystem of highland coffee production in Mesoamerica. The area is located 900-1150 m a.s.l. and receives c. $4500 \mathrm{~mm}$ rain annually, unevenly distributed in the rainy season (May to November) followed by a dry season (December to April). During the present study rainfall was not atypical for the region. In this region, coffee production is accomplished using a variety of techniques, but most often using some sort of shade tree, affording an understorey environment for the coffee bushes (Perfecto et al., 1996: Perfecto \& Armbrecht, 2003). The farm under study has over 90 species of shade trees, about $70 \%$ of which are represented by four species of Inga (Perfecto \& Vandermeer, 2008), scattered in a uniform pattern across the farm's landscape (Vandermeer et al., 2008) and casting an average of $75 \%$ shade in a relatively uniform manner throughout the farm. Consequently, the moisture regime at the level of the coffee bushes appears quite constant over the space occupied by the farm. The farm is classified as a commercial polyculture (Moguel \& Toledo, 1999) and has, according to its owner, been in this state since its foundation. All coffee bushes are Coffea arabica, cvs Typica and Bourbon, with some plants grafted onto Coffea canephora rootstocks.

In 2004, a 45-ha permanent plot was established in which a total of 10605 individual shade trees were marked and measured, involving 90 species. Several ant species nest in these shade trees, but by far the most evident is A. instabilis. Within a clump (group of Aztecaoccupied shade trees), there is a unique food-web structure that has been qualitatively characterized as follows. The ants, which nest in the shade trees and only rarely nest in the coffee bushes themselves, tend scale insects (mainly C. viridis) on nearby coffee bushes (Vandermeer \& Perfecto, 2006). Parasitic wasps (mainly two species of Encyrtidae) and a coccinelid beetle (Azya orbigera) routinely attack the scales, and reduce their local population density to almost zero in the absence of ants. The coccinelid beetle is myrmecophylous (having a tendency to be associated with ants) and is thus difficult to encounter except in the vicinity of the Azteca colonies (Liere \& Perfecto, 2008). A parasitic fly (Pseudacteon sp., Phoridae) attacks the Azteca ants, presumably reducing their numbers, and demonstrably reducing their foraging efficiency (Philpott et al., 2004), thus potentially restricting the expansion of the ant colonies.

The scale insects are routinely attacked by the white halo fungus, L. lecanii, but only when their populations are locally large, which only happens when they are under protection from the ants. In 7 years of research on this system, L. lecanii has only rarely been encountered not associated with the ant-scale mutualism, and then only on leaves and berries with especially large concentrations of scales.

Coffee rust, caused by $H$. vastatrix, is endemic in the region and is regarded by producers as a constant threat. According to the producer, rust is present, but seems to only reach important pest status in relatively small (less than $1 \mathrm{ha}$ ) patches on the farm and very irregularly from year to year.

\section{Field surveys}

Surveys were done on two different scales, one over the entire 45-ha permanent plot, and four smaller, more detailed surveys. At the large scale, a 50- $\times 50$-m grid was imposed over the whole 45-ha plot, with a shade tree located near the centre of each grid square. If $A$. instabilis nests were extant in the grid, a tree containing a nest was used as the centre, otherwise, the tree nearest the centre of the 50- $\times 50-\mathrm{m}$ plot was used as a reference. The five 
coffee bushes nearest the reference tree were sampled using the standard technique of a quasi-random harvest of 10 leaves from each bush (taken from the top, middle and bottom thirds of the bush) and recording how many of the 10 leaves exhibited uredinia of H. vastatrix (Silva-Acuña et al., 1999). Thus, each sampling point provided an estimate of number of leaves infected per 50 leaves. This large-scale survey was carried out in the dry season (February) and the wet season (July) of 2007. Previously, it had been established that ants have little preference for any particular species of shade tree, so bias from any species of shade tree is unlikely.

At the local scale, a site was first located with a clear local concentration of L. lecanii (as always, associated with a cluster of ant nests in the shade trees) and a 20$\times 10$-m plot was established in which all individual coffee bushes and all leaves on each bush were counted, recording the incidence of rust-affected leaves. Observing a significant pattern in this first plot, three other sites with clear local concentrations of L. lecanii were chosen and line transects extending out from each were established. The distance of each coffee bush from the local concentration was recorded and 100 leaves examined on each bush (beginning from the ninth branch node on the main stem, and moving downward, unless there were fewer than 100 leaves on the bush, in which case all the leaves were counted). The sampling of the bushes was done more or less along the rows of coffee bushes, at a distance of about $0-15 \mathrm{~m}$ from the centre of the L. lecanii concentration. Sampling was done in areas in which L. lecanii was evident but dispersed over many coffee bushes, rather than locally concentrated on one or a few coffee bushes. Using this approach it was reasoned that if L. lecanii was contributing to control of $H$. vastatrix through an additional input of spores to the overall system, any pattern of $H$. vastatrix infection associated with $L$. lecanii would be subtle at best, even if the overall controlling effect of L. lecanii was a major factor. Sites were also used in which there was an evident local concentration of L. lecanii in a matrix of its absence, at least in terms of visual detectability. Also, general areas were sought in which there was a range of incidence of $H$. vastatrix; two areas were found with $4-5 \%$ of leaves rusted, and two others with $22-24 \%$ of leaves rusted. These four sites were sampled in the wet season of 2007 (July), on a rectangular lattice of $20 \times 10 \mathrm{~m}$ (site 1$)$, or on transects radiating out from the centre of a $L$. lecanii concentration. Both the radiating transects and the rectangular quadrat incorporated an area that was thought to be free of L. lecanii (i.e. physically removed from the focus of $L$. lecanii attack on C. viridis). The aim of this methodology was to find any detectable signal that was a function of the distance from the concentration of L. lecanii.

Finally, for unknown reasons, L. lecanii completely disappeared at one of the four local sites by the wet season of 2008 (there was also a dramatic fall in the local population of C. viridis and what appeared to be a debilitated ant colony). Thus, whatever pattern was encountered in 2007 would be expected to disappear if L. lecanii was having an effect on its hosts, so this area was sampled again in July, 2008.

The distance from each coffee bush to the location of the nearest L. lecanii concentration was measured. In the case of site 1 there were two local concentrations within the same plot, so the distance to the nearest concentration was measured (in the other three sites there was only a single concentration of the fungus). Standard linear regression analysis was used to establish if there was a significant relationship between the incidence of coffee rust (defined as number of leaves with uredinia) and the distance to the L. lecanii concentration. In site 4 the sampling area was extended to about $40 \mathrm{~m}$ from the L. lecanii concentration to see if the basic spatial pattern held at a larger distance. In the case of the 2008 sample in site 3 , the position of the L. lecanii source in the previous year was used as the 'centre' and the distance from it to the sampled bush was measured as the independent variable.

\section{Results}

\section{Large-scale surveys}

Results of the large-scale surveys, along with the position of each ant nest, are shown in Fig. 1. There was an indication that a lower incidence of $H$. vastatrix was associated with higher incidence of ant nests at this very large scale in the dry season of 2007 (note the high density of nests in the upper left of Fig. 1a, along with the relatively low incidence of $H$. vastatrix). However, this was not verified by any statistical test. Casting the problem at several different spatial scales $(50-\times 50-, 75-\times 75-$ and $100-\times$ 100 -m quadrats), there was no statistically significant $(P \leq 0.05)$ relationship between ant-nest density and incidence of $H$. vastatrix. However, the relationship became much stronger in the wet season, as shown in Fig. 1b. Since sampling was done on bushes that were either within a restricted area around an $A$. instabilis nest or well-removed from any nest, the data were organized into two categories: 'with' or 'without ants'. The percentage incidence of coffee rust on coffee bushes near to a shade tree with ants versus that on coffee bushes far from any shade tree with ants was statistically significant $(t$-test on arcsin-transformed data, $P=0 \cdot 041$, and on a bootstrap resampling test, $P=0 \cdot 045$, sample size $=51$ bushes near trees with ants, 72 bushes far from trees with ants), which supports the data illustrated in Fig. $1 \mathrm{a}$ and $\mathrm{b}$.

\section{Small-scale surveys}

In the first small-scale plot there were two local concentrations of L. lecanii and a total of 112 sampled coffee bushes. There was a lower incidence of $H$. vastatrix when the sampled bush was nearer to L. lecanii (Fig. 2). A linear regression of incidence of $H$. vastatrix versus distance to the closest centre of L. lecanii demonstrated a significant relationship $(P<0.001)$ (Table 1$)$.

The three follow-up small-scale surveys, although less detailed with only 100 leaves examined on each bush, 
Figure 1 Results of survey of 45-ha coffee plot in (a) dry season and (b) wet season. Size of bubble proportional to incidence of coffee rust, Hemileia vastatrix. Solid circles indicate locations of shade trees containing a living nest of the ant, Azteca instabilis. Wet season pattern is statistically significant, with higher rust incidence associated with shade trees without ant colonies.
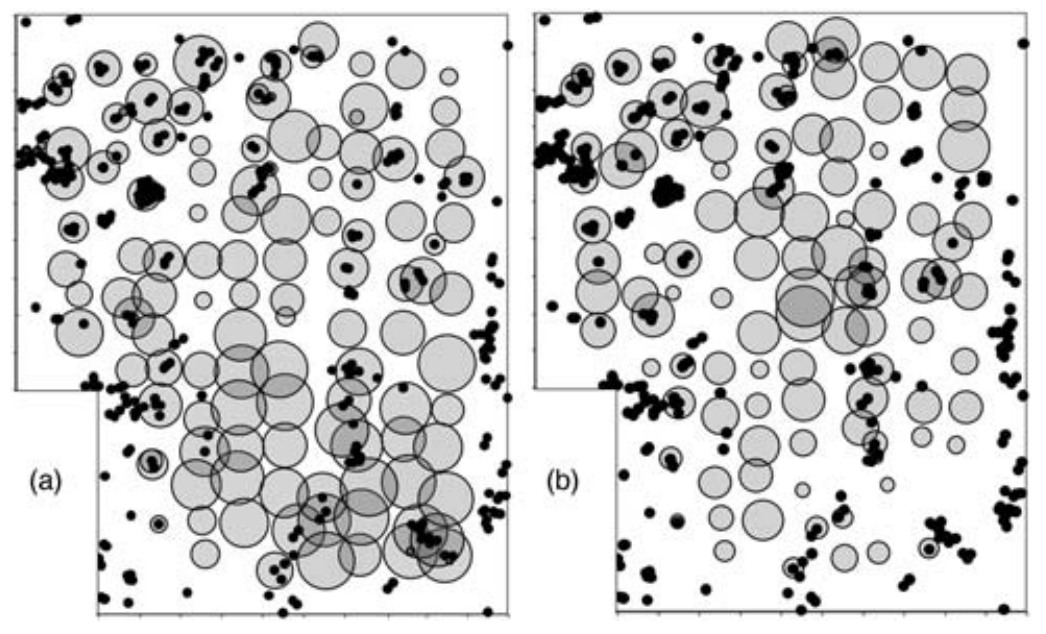

Figure 2 Bubble diagram of site $1(10-\times 20-m$ plot). Shaded bubbles indicate relative coffee rust incidence (percentage of total leaves with lesions; largest bubble is $27 \%$ ), on individual coffee bushes; hatched bubbles indicate locations of Lecanicillium lecanii infestations on Coccus viridis, with relative sizes 1,2 or 3 representing categories of infestation intensity. Larger circles indicate presumed loci of $L$. lecanii infection origin, to the centre of which the distance measured from each coffee bush.

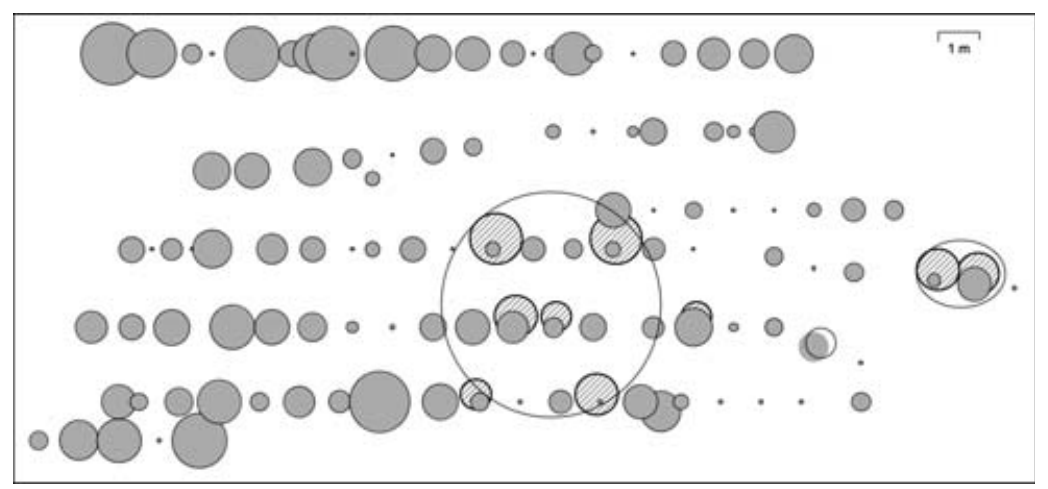

Table 1 Basic statistics for all four small-plot surveys. Site 1 is a $10-\times 20-m$ plot (Fig. 2 ) and sites $2-4$ are smaller plots extending approximately $10 \mathrm{~m}$ from the Lecanicillium lecanii concentration. Extended 4 is plot 4 extended to $20 \mathrm{~m}$ from the $L$. lecanii concentration. Site 3 was surveyed again in 2008 [3 (2008)] after L. lecanii had completely disappeared

\begin{tabular}{|c|c|c|c|c|c|}
\hline Site & No. bushes ${ }^{a}$ & Rust incidence $^{b}$ & Coefficient $^{\mathrm{C}}$ & $R^{2 \mathrm{~d}}$ & Probability ${ }^{e}$ \\
\hline 1 & 112 & $4 \cdot 68$ & 0.66 & $0 \cdot 11$ & $<0.001$ \\
\hline 2 & 30 & $4 \cdot 36$ & 0.76 & 0.12 & 0.01 \\
\hline 3 & 50 & $22 \cdot 05$ & $1 \cdot 63$ & $0 \cdot 10$ & 0.03 \\
\hline 4 & 25 & $23 \cdot 76$ & 2.95 & 0.35 & 0.002 \\
\hline Extended 4 & 51 & $22 \cdot 72$ & 0.06 & 0.03 & 0.20 \\
\hline 3 (2008) & 50 & $4 \cdot 11$ & 0.001 & 0.01 & 0.48 \\
\hline
\end{tabular}

${ }^{a}$ Total number of coffee bushes surveyed in the plot.

${ }^{b}$ Percentage of leaves containing at least one rust lesion.

${ }^{\mathrm{c}}$ Regression coefficient (slope of the least squares best fit of a linear function to the data).

${ }^{d}$ Coefficient of determination (broadly speaking, the proportion of the variance explained by the model).

eProbability of obtaining the regression coefficient by chance.

provided the same qualitative results (Table 1). Standard $\log$ scores $[(\log$ score $-\log$ mean $) / \log$ mean] for all bushes at all four sites are shown in Fig. 3. It can be seen that there is a great deal of scatter in the relationship and that the explanatory power of this variable is low.

All four surveys were carried out so that the concentration of L. lecanii was within about $10 \mathrm{~m}$ of all coffee bushes. An additional group of bushes was surveyed in the case of site 4 , involving individual bushes ranging as far as $20 \mathrm{~m}$. When the latter were included, the statistical signi- ficance of the regression was lost for this site (Table 1), suggesting that the scaling of the input of $L$. lecanii into the environment may be of the order of $10 \mathrm{~m}$. This did not detract, however, from the conclusion that the basic mutualist system of the ant and scale insect contributed to the overall standing crop of L. lecanii spores more generally in the plantation.

Site 3 was resurveyed in 2008 after L. lecanii had disappeared and the relationship with distance to the spot where $L$. lecanii had been the year before was not signficant 


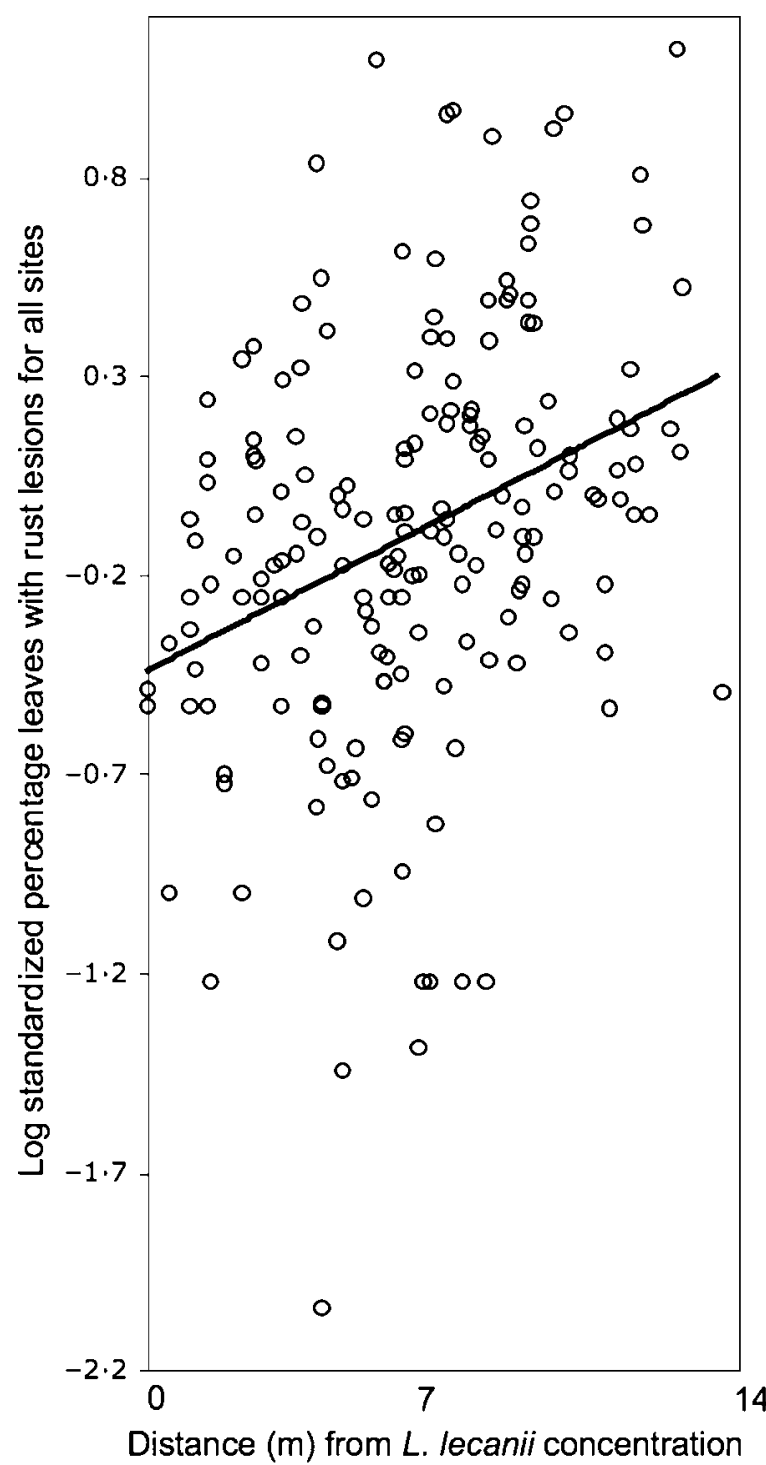

Figure 3 Log-standardized percentage incidence of coffee leaves with rust lesions as a function of distance from Lecanicillium lecanii concentrations $\left(R^{2}=0 \cdot 108, P=0 \cdot 00006\right)$, from all mapped points.

(Table 1), suggesting that L. lecanii affects the incidence of coffee rust.

\section{Discussion}

It appears that there may be at least partial control of $H$. vastatrix by L. lecanii, which is enhanced through the existence of the mutualistic association of the ant, A. instabilis, with the green coffee scale, C. viridis.

Definitive proof that the same isolates of L. lecanii that colonize $C$. viridis are able to attack $H$. vastatrix has not yet been reported. Previously, Gonzales et al. (1995) reported morphological differences between isolates collected from $C$. viridis and those from $H$. vastatrix. However, Cortez-Madrigal et al. (2003) found these morphological characteristics highly variable among insect-derived isolates. Furthermore, in at least one study (Eskes et al., 1991) the same isolate of L. lecanii that attacked $H$. vastatrix was obtained from insects. The results of the present study lend tentative support to the suggestion that the isolates of $L$. lecanii that attack $C$. viridis are also effective at hyperparasitism of $H$. vastatrix. It also supports the view of Andrews (1992) that immigration, as opposed to local population growth, may be important for microbial biological control.

Given the generalized distribution of the ant over this particular coffee farm (and other shaded farms in the region are similar), this mutualism may be a previously unrecognized, yet important, contributor to the generalized dynamics of $H$. vastatrix, adding to the large set of well-known factors already shown to be influential (Avelino et al., 2004). While the specific local effect operates over a short distance (seemingly about $10 \mathrm{~m}$ ), this effect is useful only to demonstrate that the phenomenon actually exists. From a practical point of view, the mutualism is just one of a host of potential contributors to the overall spore density of L. lecanii in the region. Since L. lecanii seems to attack a relatively broad range of insects and other fungi (Eskes et al., 1991; Gonzales et al., 1995; Cortez-Madrigal et al., 2003), it is possible that its multiplication occurs on a range of other species, each of which contributes in a small way to the standing crop of L. lecanii spores in the environment.

The importance of these results goes beyond the practical issue of biological control. Although it has long been known that natural enemies are important forces in the maintenance of the non-epidemic status of coffee rust, the role of complex ecological interactions has not been emphasized. This study presents evidence for such a role involving a key ant-hemipteran mutualism that operates to allow L. lecanii to become locally abundant, thus contributing to the overall standing crop of the spores of this hyperparasite of $H$. vastatrix. These results demonstrate that there is a functional aspect in the associated biodiversity of this agroecosystem, albeit a subtle one.

\section{References}

Andrews JH, 1992. Biological control in the phyllosphere. Annual Review of Phytopathology 30, 603-5.

Avelino J, Willocquet L, Savary S, 2004. Effects of crop management patterns on coffee rust epidemics. Plant Pathology 53, 541-7.

Blakeman JP, Fokkema NJ, 1982. Potential for biological control of plant diseases on the phylloplane. Annual Review of Phytopathology 20, 167-92.

Cortez-Madrigal H, Alatorre-Rosas R, Mora-Aguilera G, Bravo-Mojica H, Ortiz-Garcia CF, Aceves-Navarro LA, 2003. Characterization of multisporic and monosporic isolates of Lecanicillium (= Verticillium) lecanii for the management of Toxoptera aurantii in cocoa. BioControl 48, 321-34.

Eskes AB, Mendes MDL, Robbs CF, 1991. Laboratory and field studies on parasitism of Hemileia vastatrix with Lecanicillium lecanii and V. leptobactrum. Café Cacao Thé 35, 275-82. 
Fulton RH, 1984. Coffee Rust in the Americas. St Paul, MN, USA: APS Press.

Gonzales E, Breavo N, Carone M, 1995. Caracterización de Lecanicillium lecanii (Zimm.) Viegas hiperparasitando Hemileia vastatrix Berk y $\mathrm{Br}$ y Coccus viridis Green. Revista de Protección Vegetal 10, 169-71.

Kouvelis VN, Zare R, Bridge PD, Typas MA, 1999. Differentiation of mitochondrial subgroups in the Verticillium lecanii species complex. Letters in Applied Microbiology 28, 263-8.

Kushalappa AC, Eskes AB, 1989. Advances in coffee rust research. Annual Review of Phytopathology 27, 503-31.

Liere H, Perfecto I, 2008. Cheating on a mutualism: indirect benefits of ant attendance to a coccicophagous coccinellid. Environmental Entomology 37, 143-9.

McCook S, 2006. Global rust belt: Hemileia vastatrix and the ecological integration of world coffee production since 1850 . Journal of Global History 1, 177-95.

Moguel P, Toledo VM, 1999. Biodiversity conservation in traditional coffee systems of Mexico. Conservation Biology 13, 11-21.

Mor H, Gindin G, Ben-Ze'ev IS et al., 1996. Diversity among isolates of Verticillium lecanii as expressed by DNA polymorphism and virulence towards Bemisia tabaci. Phytoparasitica 24, 111-8.

Perfecto I, Armbrecht I, 2003. The coffee agroecosystem in the
Neotropics: combining ecological and economic goals. In: Vandermeer J, ed. Tropical Agroecosystems. Boca Raton, FL, USA: CRC Press, 159-94.

Perfecto I, Vandermeer J, 2008. Spatial pattern and ecological process in the coffee agroecosystem. Ecology 89, 915-20.

Perfecto I, Rice R, Greenberg R, Van der Voolt M, 1996. Shade coffee as refuge of biodiversity. BioScience 46, 589-608.

Philpott SM, Maldonado J, Vandermeer J, Perfecto I, 2004. Taking trophic cascades up a level: behaviorally-modified effects of phorid flies on ants and ant prey in coffee agroecosystems. Oikos 105, 141-7.

Shaw DE, 1987. Lecanicillium lecanii a hyperparasite on the coffee rust pathogen in Papua New Guinea. Australasian Plant Pathology 17, 2-3.

Silva-Acuña R, Maffia LA, Zambolim L, Berger RD, 1999. Incidence-severity relationships in the pathosystem Coffea arabica-Hemileia vastatrix. Plant Disease 83, 186-8.

Vandermeer J, Perfecto I, 2006. A keystone mutualism drives pattern in a power function. Science 17, 1000-2.

Vandermeer J, Perfecto I, Philpott SM, 2008. Clusters of ant colonies and robust criticality in a tropical agroecosystem. Nature 451, 457-9.

Zare R, Gams W, 2001. A revision of Verticillium sect. Prostrata. IV. The genus Lecanicillium and the new genus Simplicillium. Nova Hedwigia 73, 1-50. 